\title{
Effect of $\mathrm{Ti}^{4+}$ Doping on Structural, Electrical and Magnetic Properties of $\mathrm{Ni}_{0.4} \mathrm{Cu}_{0.2} \mathrm{Zn}_{0.4} \mathrm{Fe}_{2-x} \mathrm{Ti}_{x} \mathrm{O}_{4}$ Ferrites
}

\section{Sajal Chandra Mazumdar ${ }^{1}$, Farhad Alam², Umma Habiba Tanni ${ }^{1}$, Kamrunnahar Kali', Bablu Chandra Das ${ }^{3}$, Mohammed Nazrul Islam Khan ${ }^{4}$}

\author{
${ }^{1}$ Department of Physics, Comilla University, Cumilla, Bangladesh \\ ${ }^{2}$ Department of Physical Sciences, School of Engineering and Computer Science, Independent University, \\ Dhaka, Bangladesh \\ ${ }^{3}$ Departments of Physics, Bangladesh University of Engineering and Technology, Dhaka, Bangladesh \\ ${ }^{4}$ Materials Science Division, Atomic Energy Centre, Dhaka, Bangladesh \\ Email: *sajalf@yahoo.com
}

How to cite this paper: Mazumdar, S.C. Alam, F., Tanni, U.H., Kali, K., Das, B.C. and Khan, M.N.I. (2019) Effect of $\mathrm{Ti}^{4+}$ Doping on Structural, Electrical and Magnetic Properties of $\mathrm{Ni}_{0.4} \mathrm{Cu}_{0.2} \mathrm{Zn}_{0.4} \mathrm{Fe}_{2-x} \mathrm{Ti}_{x} \mathrm{O}_{4}$ Ferrites. Materials Sciences and Applications, 10, 733-745.

https://doi.org/10.4236/msa.2019.1012053

Received: October 24, 2019

Accepted: November 26, 2019

Published: November 29, 2019

Copyright (c) 2019 by author(s) and Scientific Research Publishing Inc. This work is licensed under the Creative Commons Attribution International License (CC BY 4.0).

http://creativecommons.org/licenses/by/4.0/

\begin{abstract}
$\mathrm{Ti}^{4+}$ doped $\mathrm{Ni}_{0.4} \mathrm{Cu}_{0.2} \mathrm{Zn}_{0.4} \mathrm{Fe}_{2-x} \mathrm{Ti}_{x} \mathrm{O}_{4}(x=0.0,0.02,0.05,0.07,0.10)$ chemical compositions are prepared by conventional solid state reaction technique. The ferrite phase formation has been confirmed from the pattern of XRD. The theoretical density $\left(\rho_{t h}\right)$, bulk density $\left(\rho_{B}\right)$, and porosity are calculated from the XRD data and using approximate formulas. Value of $\rho_{t h}$ is found to be greater than the value of $\rho_{B}$ indicating the formation of pores inside the bulk specimens. The micro-structural investigation has been done using Field Emission Scanning Electron Microscope and it is found that the average grain size reduces with the increase of Ti content. Saturation magnetization $\left(M_{s}\right)$ also reduces with the increase of Ti content, contrarily remanent magnetization $\left(M_{r}\right)$ and coercivity $\left(H_{c}\right)$ increases with the concentration of $\mathrm{Ti}$ in the composition due to the pinning effect. The real part of the initial permeability is found to be maximum for the $x=0.02$ sample which could be due to the homogeneity and high density of the sample. For increasing frequency, the dielectric constant and dielectric loss are observed to decrease.
\end{abstract}

\section{Keywords}

Ferrite, X-Ray Diffraction, VSM, SEM, Dielectric Properties, Magnetization

\section{Introduction}

Polycrystalline Nickel-Copper-Zinc ferrite is a semi-conducting material that 
possesses high eddy current losses and high electrical resistivity, and shows skin effect. Metal doped Nickel-Copper-Zinc ferrites are very important for their wide applications in technology. They can be used as inductors, particularly as Multilayer Chip Inductor (MLCI), transformer core, recording heads and storage devices and in diagnosis purposes [1] [2] [3]. They are also attractive in research and technology for their high magnetic permeability, low magnetic losses, lower cost and easy manufacturing process and for superior magnetization properties [4] [5].

Mixed metal oxides with iron $\left(\mathrm{Fe}^{3+}\right)$ oxide with the general formula $\mathrm{MFe}_{2} \mathrm{O}_{4}$ are known as Ferrites. They exhibit spinel structure and hence are also named as spinel ferrites. It is non-conducting ferromagnetic ceramic composites obtained from hematite $\left(\mathrm{Fe}_{2} \mathrm{O}_{3}\right)$ or magnetite $\left(\mathrm{Fe}_{3} \mathrm{O}_{4}\right)$ and oxides of other transition metals. Such ceramics are fragile and strong. Ferrites are technically very important because they exhibit spontaneous magnetization below the Curie temperature. There is a continuous interest on development of ferrites with excellent electrical and magnetic properties due to their potential applications. Actually the size, shape and structure of the material determine these properties [6]. General formula to represent a binary oxide spinel is $\mathrm{A}_{1-x} \mathrm{~B}_{x}\left[\mathrm{~A}_{x} \mathrm{~B}_{2-x}\right] \mathrm{O}_{4}$; here $x$ is called degree of inversion. For $x=0$, it's a normal spinel, whereas for $x=1$ it's an inverse spinel. A physical property of the ferrite depends on cation distribution on the sites, doping, and particle size and also on the method of preparation of the composition of the ferrite [7] [8] [9]. Nature of the dopant can also influence the ultimate magnetic and electrical characteristics [10] [11]. Ionic radius and valiancy of the substituted ion also affect the alteration of these magnetic properties along with its site of preference [12] [13] [14]. Ti doped Ni-Cu-Zn ferrites are quite important in the field of microwave industry which is a mixture of $\mathrm{NiFe}_{2} \mathrm{O}_{4}, \mathrm{ZnFe}_{2} \mathrm{O}_{4}, \mathrm{CuFe}_{2} \mathrm{O}_{4}$ with long range ferromagnetic ordering. Rathi et al. [15] investigated the stuctrural, electric and magnetic properties of Ti doped $\mathrm{Ni}-\mathrm{Cu}-\mathrm{Zn}$ ferrite. The dielectric constants are found to vary as a function of frequency and composition at room temperature. It is observed that with the increase in the concentration of $\mathrm{Ti}^{4+}$ ions, the dielectric constant increases. On the other hand the saturation magnetization decreases with the increasing concentration of $\mathrm{Ti}^{4+}$ ions. $\mathrm{Fe}^{3+}$ is replaced by $\mathrm{Ti}^{4+}$ in $\mathrm{Ni}_{0.4} \mathrm{Cu}_{0.2} \mathrm{Zn}_{0.4} \mathrm{Fe}_{2-x} \mathrm{Ti}_{x} \mathrm{O}_{4}, \mathrm{Ti}^{4+}$ ions preferentially occupy the octahedral site and the $\mathrm{Fe}^{3+}$ ions are displaced to the tetrahedral sites. In this paper, synthesis of $\mathrm{Ni}_{0.4} \mathrm{Cu}_{0.2} \mathrm{Zn}_{0.4} \mathrm{Fe}_{2-x} \mathrm{Ti}_{x} \mathrm{O}_{4}(x=0.0$, $0.02,0.05,0.07,0.10)$ by conventional solid state reaction technique and the effect of Ti substitution on structural, morphological, electrical and magnetic properties of $\mathrm{Ni}-\mathrm{Cu}-\mathrm{Zn}$ ferrites have been discussed.

\section{Experimental Procedure}

\subsection{Synthesis}

Solid state reaction technique is assumed to synthesis $\mathrm{Ti}^{4+}$ substituted $\mathrm{Ni}-\mathrm{Cu}-\mathrm{Zn}$ ferrites of stoichiometric compositions $\mathrm{Ni}_{0.4} \mathrm{Cu}_{0.2} \mathrm{Zn}_{0.4} \mathrm{Fe}_{2-x} \mathrm{Ti}_{x} \mathrm{O}_{4}(x=0.0,0.02$, $0.05,0.07,0.10)$ in the present study. $\mathrm{Ni}_{2} \mathrm{O}_{3}(99.99 \%), \mathrm{CuO}(99.99 \%), \mathrm{ZnO}, \mathrm{TiO}_{2}$, 
$\mathrm{Fe}_{2} \mathrm{O}_{3}$ are used as raw materials for the preparation of $\mathrm{Ni}-\mathrm{Cu}-\mathrm{Zn}$ ferrites. The constituent components in required stoichiometric proportions are weighted and the weighted powders are mixed mechanically by milling to decrease the particle size of the powders to the micron range. For this preparation, mortar and pestle are used for milling operation and each sample was milled for 6 hours. The resulting powder is calcined at $800^{\circ} \mathrm{C}$ for 4 hours and grounded into fine powder by milling for 2 hours. Grounded powder is then used in X-ray diffractometer for XRD for phase identification, Scanning Electron Microscope (SEM) for micro-structural investigation and Vibrating Sample Magnetometer (VSM) for magnetic properties measurement. For the investigation of dielectric properties, the powders are then pressed into disc and toroid shaped sample at a pressure of $10-15 \mathrm{KN} / \mathrm{m}^{2}$. These disc and toroid are sintered at $1200^{\circ} \mathrm{C}$ for 4 hours.

\subsection{Measurements Technique}

XRD was performed using PHILIPS PW $3040 \mathrm{X}$-ray diffractometer with $\mathrm{Cu}-\mathrm{K} \alpha$ radiation in the range $5^{\circ}$ to $70^{\circ}$. Lattice parameter $\left(a_{0}\right)$, theoretical density $\left(\rho_{t h}\right)$, porosity $(P)$, bulk density $\left(\rho_{B}\right)$ were calculated for all the samples using the following Equations (1)-(5) and were tabulated in Table 1 [16].

$$
\begin{gathered}
d_{h k l}^{2}=\frac{a^{2}}{h^{2}+k^{2}+l^{2}} \quad \text { (For cubic spinel) } \\
F(\theta)=\frac{1}{2}\left(\cos ^{2} \theta / \sin \theta\right)+\left(\cos ^{2} \theta / \theta\right) \\
\rho_{\text {th }}=\frac{8 M}{N_{A} a_{0}^{3}} \mathrm{~g} / \mathrm{cm}^{3} \\
P(\%)=\frac{\left(\rho_{x}-\rho_{B}\right)}{\rho_{x}} \times 100 \% \\
\rho_{B}=\frac{m}{\pi r^{2} t}
\end{gathered}
$$

where $h, k$ and $l$ represent the crystal plane's Miller indices, $N_{A}$ denotes the number of Avogadro, $M$ means molecular weight, $a_{0}$ is the lattice constant of spinel structure, $m$ equal mass, $r$ indicates radius and $t$ signifies the pellet or ring thickness [16].

Table 1. The structural parameters of $\mathrm{Ni}_{0.4} \mathrm{Cu}_{0.2} \mathrm{Zn}_{0.4} \mathrm{Fe}_{2-x} \mathrm{Ti}_{x} \mathrm{O}_{4}$ ferrites.

\begin{tabular}{ccccc}
\hline $\begin{array}{c}\text { Ti Content } \\
(\boldsymbol{x})\end{array}$ & $\begin{array}{c}\text { Lattice } \\
\text { Parameter }(\AA)\end{array}$ & $\begin{array}{c}\text { Theoretical } \\
\text { density, } \rho_{t h},\left(\mathrm{~g} / \mathrm{cm}^{3}\right)\end{array}$ & $\begin{array}{c}\text { Bulk Density, } \rho_{b} \\
\left(\mathrm{~g} / \mathrm{cm}^{3}\right)\end{array}$ & $\begin{array}{c}\text { Porosity }(\%) \\
\left(\rho_{t h}-\rho_{B} / \rho_{t h}\right) \times 100\end{array}$ \\
\hline 0.00 & 8.36 & 5.41 & 4.49 & 17.01 \\
0.02 & 8.34 & 5.45 & 4.44 & 18.53 \\
0.05 & 8.37 & 5.38 & 4.46 & 17.10 \\
0.07 & 8.39 & 5.34 & 4.51 & 15.54 \\
0.10 & 8.39 & 5.34 & 4.52 & 15.36 \\
\hline
\end{tabular}


The grain structures of the sample were visualized under Field Emission Scanning Electron Microscope (FESEM). Measurement of the magnetic hysteresis loop and the magnetic properties of the materials were performed using a Vibrating Sample Magnetometer (VSM) within a range of $10 \mathrm{kOe}(1 \mathrm{Tesla})$. For dielectric tests, etched, well-polished pellets were used. For good electrical contact, silver paste had been used on both sides of the samples. Wayne Kerr Impedance Analyzer is used to carry dielectric measurements at room temperature in the frequency ranged $1 \mathrm{kHz}$ to $100 \mathrm{kHz}$. The variation of dielectric properties (dielectric constant, dielectric loss) and magnetic properties (magnetic loss, relative quality factor, resistivity) for all the samples were measured and calculated using the following Equations (6)-(9) [2] [3].

$$
\begin{gathered}
\text { Dielectric constant, } \varepsilon^{\prime}=\frac{C}{C_{0}} \\
\text { Dielectric loss, } \tan \delta_{E}=\frac{\varepsilon^{\prime \prime}}{\varepsilon^{\prime}} \\
\text { RQF, RQF }=\frac{\varepsilon^{\prime}}{\tan \delta_{E}} \\
\text { Resistivity, } \rho=\frac{R A}{l}
\end{gathered}
$$

where, $C$ is the capacitance of the samples and $C_{0}$ is the capacitance of the capacitor without the dielectric materials and $C_{0}=\varepsilon_{0} A / l, \epsilon_{0}$ is the permittivity of the free space and $A=\pi r^{2}$ is the area of the cross section of the pellet shaped sample, $R$ is the resistance of the sample, $l$ is the thickness of the pellets and $A$ is the surface area.

The measurement of complex permeability of the ring shaped samples was performed at room temperature in the frequency range from $1 \mathrm{KHz}$ to $100 \mathrm{MHz}$ using the following formulas,

$$
\text { Real part, } \mu_{i}^{\prime}=\frac{L_{s}}{L_{0}}
$$

Imaginary part,

$$
\mu_{i}^{\prime \prime}=\mu_{i}^{\prime} \tan \delta_{M}
$$

where, $L_{S}$ is the inductance of the sample and $L_{o}=\frac{\mu_{0} N^{2} S}{\pi \bar{d}}$ and that is derived from geometric of the samples, $L_{0}$ is the inductance of the winding coil except the sample, $N$ represents the number of turns of the coil $(N=5), S$ indicates the cross sectional area of the ring shaped samples as given below,

$$
S=d \times h
$$

And

$$
d=\frac{d_{2}-d_{1}}{2}
$$

where, $d_{1}$ is the inner diameter and $d_{2}$ is the outer diameter, $h$ represents the height of the ring. Again, $\bar{d}$ indicates the mean diameter of the toroidal sample 
and can be written as,

$$
\bar{d}=\frac{d_{1}+d_{2}}{2}
$$

Then Equation (10) can be written as

$$
\mu_{i}^{\prime}=\frac{\pi L_{S} \bar{d}}{\mu_{0} N^{2}\left(\frac{d_{2}-d_{1}}{2}\right) h}
$$

\section{Results and Discussion}

\subsection{Phase and Density Analysis}

X-ray diffraction pattern of $\mathrm{Ni}_{0.4} \mathrm{Cu}_{0.2} \mathrm{Zn}_{0.4} \mathrm{Fe}_{2-x} \mathrm{Ti}_{x} \mathrm{O}_{4}(x=0.0,0.02,0.05,0.07$, $0.10)$ ferrite is shown in Figure 1. In XRD patter, from the reflected peaks it is clear that the samples are of crystalline cubic spine structure. Having differences in the ionic radius of $\mathrm{Ti}^{4+}(0.68 \AA)$ with that of $\mathrm{Fe}^{3+}(0.64 \AA)$, there is an increasing trend of lattice parameter $a_{0}$ of the lattice with increase in $\mathrm{Ti}^{4+}$ concentration. The increase in lattice parameter could be ascribed to $\mathrm{Ti}^{4+}$ ions can be located at the boundaries of grain [16]. That's why it hinders the growth of grain and increases the rinsing of grains and the tips to increase the lattice parameter.

Figure 2 shows that lattice parameter increases with the Ti content except $x=$ 0.02 . It has been observed by Mali et al. that the rise of the crystallite size with the substitution of $\mathrm{Ti}^{4+}$ is attributed to the substituting of $\mathrm{Ti}^{4+}(0.68 \AA)$ at $\mathrm{Fe}^{3+}$ (0.64 ̊) site [17].

Figure 3 illustrates the variation of bulk and theoretical densities of $\mathrm{Ni}_{0.4} \mathrm{Cu}_{0.2} \mathrm{Zn}_{0.4} \mathrm{Fe}_{2-x} \mathrm{Ti}_{x} \mathrm{O}_{4}(x=0.0,0.02,0.05,0.07,0.10)$. From this figure it is observed that theoretical density of these samples reduces almost linearly with the concentration of Ti except for $x=0.02$. Theoretical density decreases because the atomic mass of Ti $(47.867 \mathrm{~g} / \mathrm{mol})$ is less than that of Fe $(55.845 \mathrm{~g} / \mathrm{mol})$. And for $x$ $=0.02$, the theoretical density rises because in this case the lattice constant $\left(a_{0}\right)$ decreases. From Figure 3, it has also been noted that bulk density of these samples rises linearly with the concentration of Ti except for $x=0.02$ and $x=0.05$. It is obvious that theoretical density is higher than bulk density, this variation is explained in the way that when the samples were sintered, they may contain crack and microscopic pores and lattice vacancies on the atomic scale [18]. But theoretical density which is precisely measured from lattice parameter and unit cell volume of the sample is free from these defects.

Figure 4 represents the variant of the porosity and bulk density $\left(\rho_{B}\right)$ with the concentration of $\mathrm{Ti}$. The variant of $\rho_{B}$ with the concentration of Ti might be understood from the microstructure. The bulk density decreases initially for $x=$ 0.02 and $x=0.05$ and for these two samples the microstructure contains intergranular porosity. Intra-granular porosity leading to poor mechanical and magnetic properties is practically impossible to eliminate [19]. When the growth rate of the grain is very high, the pores may be left behind the rapidly moving grain boundary and trapped inside the grain. The increase of bulk density for $x=0.07$ 
and $x=0.10$ is due to the compact microstructure of the samples. It is evident from Figure 4, that the $\rho_{B}$ and porosity show the opposite behavior to each other. The structural parameters of $\mathrm{Ni}_{0.4} \mathrm{Cu}_{0.2} \mathrm{Zn}_{0.4} \mathrm{Fe}_{2-x} \mathrm{Ti}_{x} \mathrm{O}_{4}$ ferrites have been presented in Table 1.

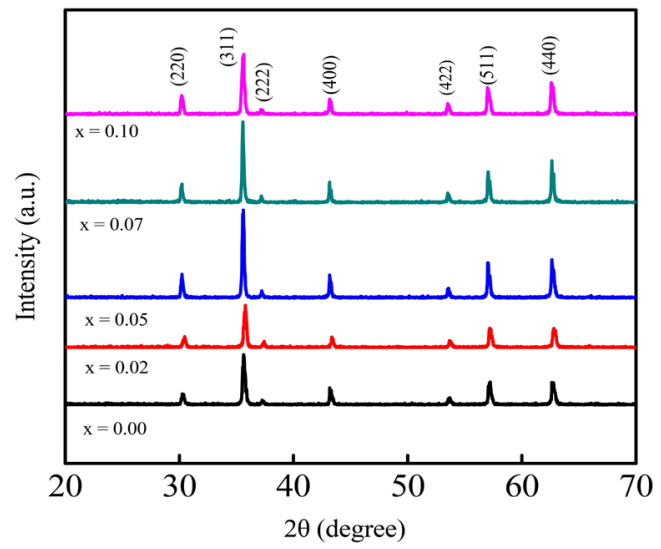

Figure 1. XRD pattern of $\mathrm{Ni}_{0.4} \mathrm{Cu}_{0.2} \mathrm{Zn}_{0.4} \mathrm{Fe}_{2-X} \mathrm{Ti}_{X} \mathrm{O}_{4}$ ferrites.

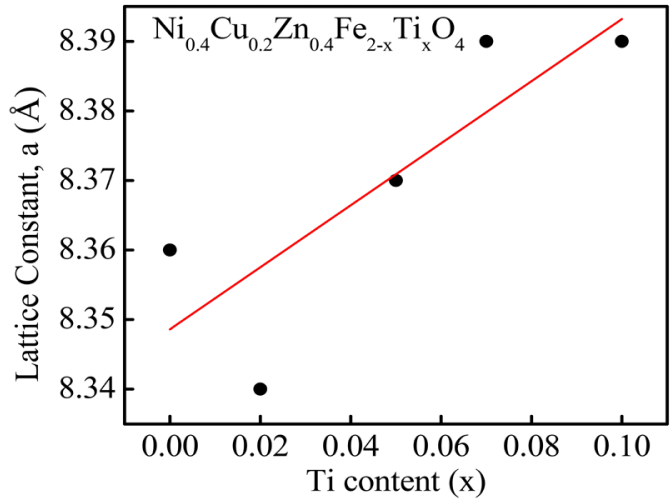

Figure 2. Variation of lattice parameter depending on the concentration of Ti.

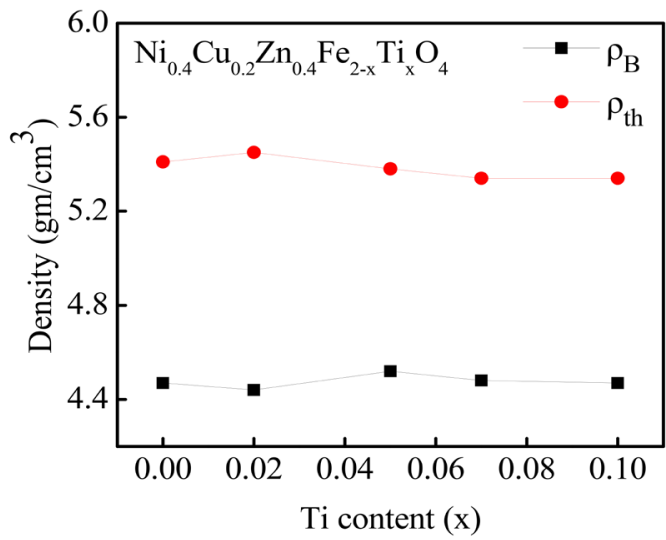

Figure 3. Variation of density depending on the concentration of $\mathrm{Ti}$. 


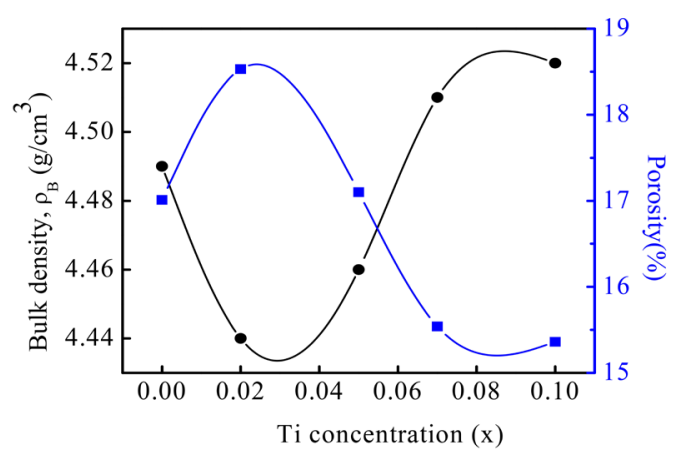

Figure 4. Variation of porosity and bulk density as a function of Ti content.

\subsection{Particle Size Analysis}

Scanning Electron Microscopy of $\mathrm{Ni}_{0.4} \mathrm{Cu}_{0.2} \mathrm{Zn}_{0.4} \mathrm{Fe}_{2-x} \mathrm{Ti}_{x} \mathrm{O}_{4}(x=0.0,0.02,0.05$, $0.07,0.10)$ compositions with $5000 \times$ magnification are shown in Figure 5. Micro structural images of $\mathrm{Ni}-\mathrm{Cu}-\mathrm{Zn}$-Ti ferrite samples are taken for morphological study, so that an insight of grain structures can be seen. The average grain size $(D)$ of the samples is estimated using a linear intercept technique [20]. Value of $D$ reduces with the increase in concentration of Ti except for $x=0.02$ and decreases from $18.89 \mu \mathrm{m}$ to $10.85 \mu \mathrm{m}$ (for $x=0.02$ the grain size is $19.76 \mu \mathrm{m}$ ). Pores at grain boundary becomes very less when the grain size is smaller. The addition of Ti content might have suppressed the growth of grain boundary. Hence, the $D$ reduces with the increase in concentration of Ti. Decrease in $D$ could also be due to a decrease in oxygen vacancy [21].

\subsection{Hysteresis Loops}

Hysteresis loops (M-H) of different ferrite samples are shown in Figure 6. Saturation magnetizations $\left(\mathrm{M}_{\mathrm{s}}\right)$, Coercivity $\left(\mathrm{H}_{\mathrm{c}}\right)$, Anisotropy constant $(\mathrm{K})$ and Remanent magnetization $\left(\mathrm{M}_{\mathrm{r}}\right)$ of $\mathrm{Ni}_{0.4} \mathrm{Cu}_{0.2} \mathrm{Zn}_{0.4} \mathrm{Fe}_{2-x} \mathrm{Ti}_{x} \mathrm{O}_{4}$ are measured and tabulated in Table 2. From Table 2 we see that the samples have low $H_{c}$ and high $M_{s}$ that enable them to be used as soft magnetic materials. From Table 2, it's also noted that, though the $\left(\mathrm{M}_{\mathrm{s}}\right)$ is decreased with the concentration of Ti but coercivity $\left(H_{c}\right)$ is increased except for $x=0.02$ i.e.; there is an inverse relationship between $M_{s}$ and $H_{c}$ as shown in Figure 7.

It could be concluded that value of coercivity rises with the rising concentration of Ti except for $x=0.02$ due to the enough defects or porosity in the sample. Moreover, as can be seen clearly in Figure 8 that anisotropy $\mathrm{K}$ reduces with increase in Ti concentration due to decreasing grain size which is evident from SEM images.

\subsection{Magnetic Permeability}

Figure 9(a), Figure 9(b) and Figure 9(c) illustrate the frequency dependency of initial permeability $\left(\mu_{i}\right)$, relative quality factor (RQF), magnetic loss tangent ( $\tan \delta$ ) for $\mathrm{Ni}_{0.4} \mathrm{Cu}_{0.2} \mathrm{Zn}_{0.4} \mathrm{Fe}_{2-x} \mathrm{Ti}_{x} \mathrm{O}_{4}$ under work. From Figure 9(a), it is seen that 
the permeability increases with Ti substitution of $x=0.02$ and $x=0.05$ and it reduces for $x=0.07$ and $x=0.10$. The $\mu_{i}$ of a ferrite depends on average grain size, intra-granular porosity, domain walls bulging and reversible domain walls displacement etc. [22].
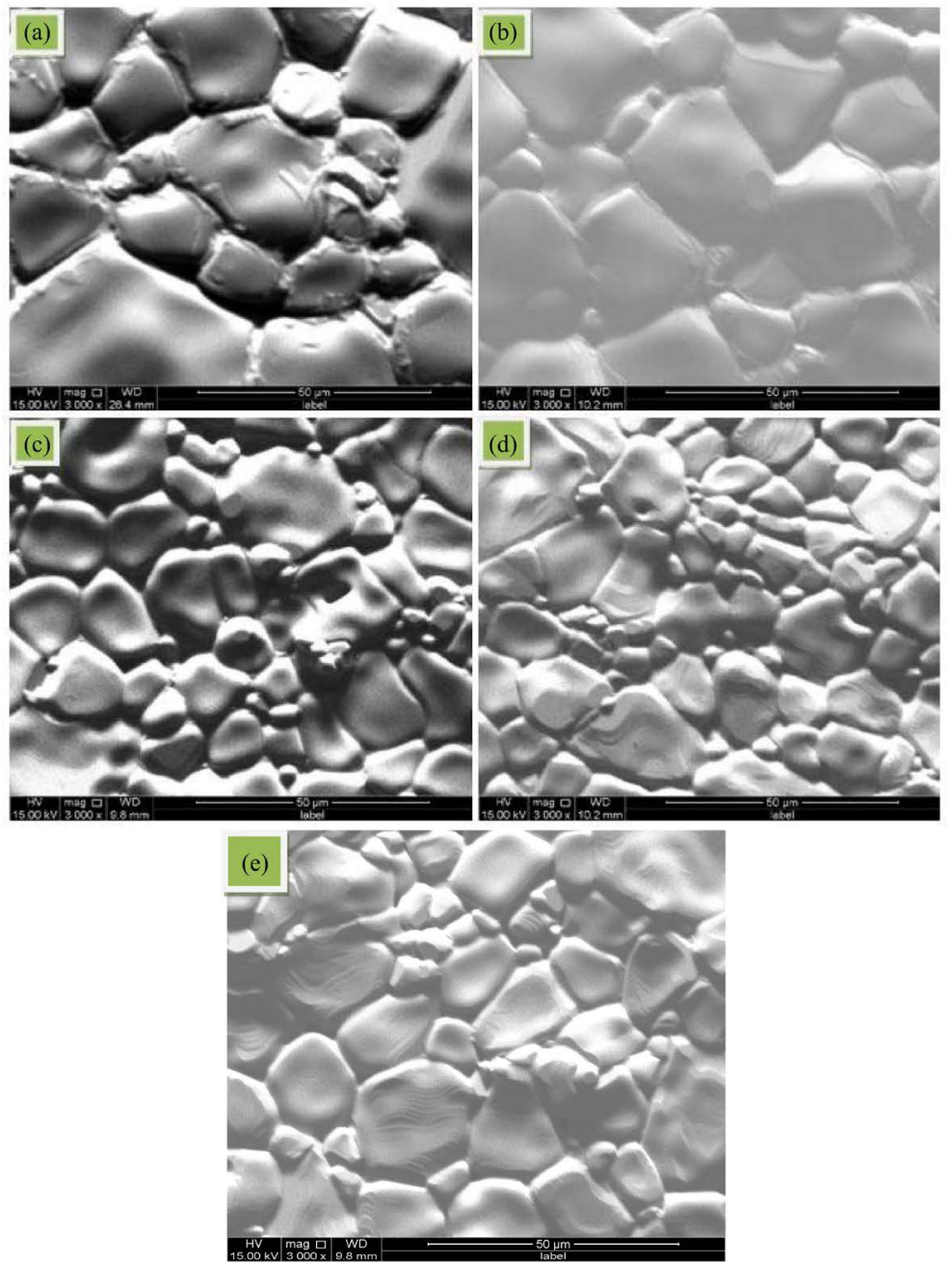

Figure 5. Scanning electron microscope images of $\mathrm{Ni}_{0.4} \mathrm{Cu}_{0.2} \mathrm{Zn}_{0.4} \mathrm{Fe}_{2-x} \mathrm{Ti}_{x} \mathrm{O}_{4}$ for $x=0.00$ to 0.10 , respectively.

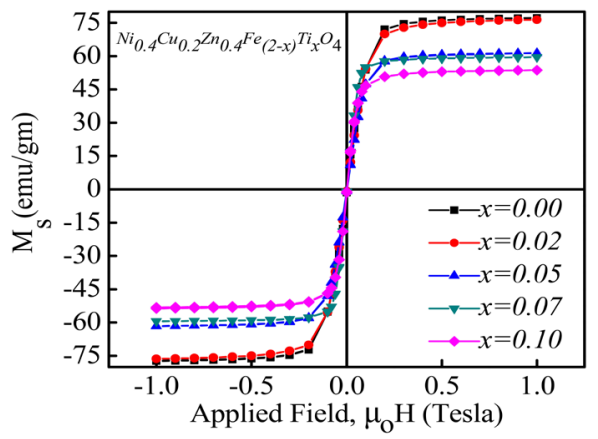

Figure 6. M-H loop of $\mathrm{Ni}_{0.4} \mathrm{Cu}_{0.2} \mathrm{Zn}_{0.4} \mathrm{Fe}_{2-x} \mathrm{Ti}_{x} \mathrm{O}_{4}$, ferrite for $x=0.0, x$ $=0.02, x=0.05, x=0.07, x=0.10$ respectively at room temperature. 


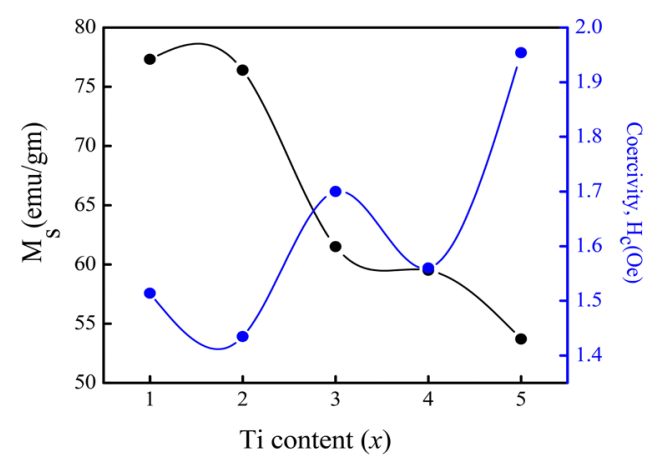

Figure 7. Variation of $\mathrm{M}_{\mathrm{s}}$ and $\mathrm{H}_{\mathrm{c}}$ with Ti content.

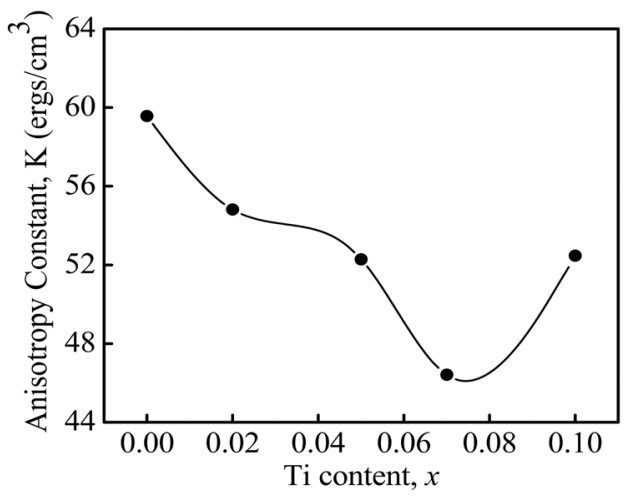

Figure 8. Variation of anisotropy constant (K) with the concentration of Ti.
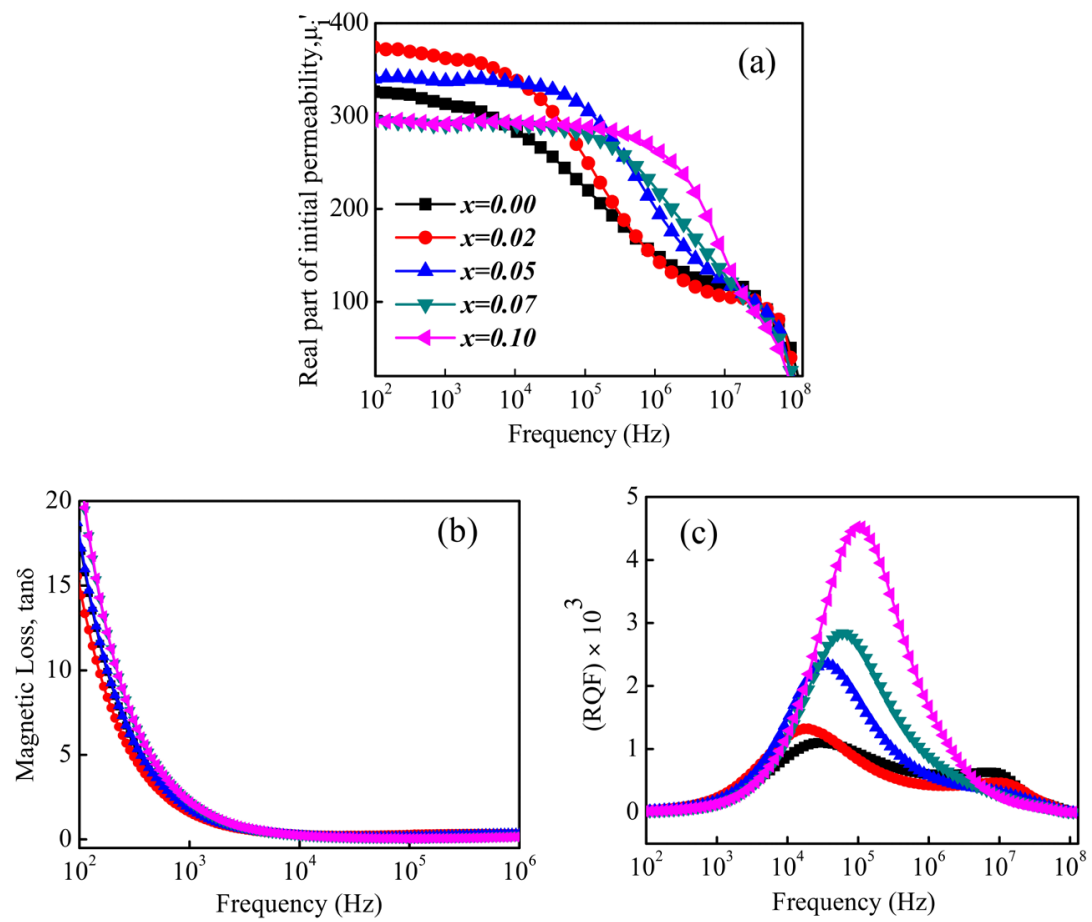

Figure 9 (a) Variation of $\mu_{i}^{\prime}$ with frequency; (b) Magnetic loss tangent ( $\tan \delta$ ) with frequency; (c) Frequency variable Relative Quality Factor (RQF). 
Table 2. Saturation magnetization, coercivity, anisotropy constant and remanent magnetization of $\mathrm{Ni}_{0.4} \mathrm{Cu}_{0.2} \mathrm{Zn}_{0.4} \mathrm{Fe}_{2-x} \mathrm{Ti}_{X} \mathrm{O}_{4}(x=0.0,0.02,0.05,0.07,0.10)$.

\begin{tabular}{ccccc}
\hline $\begin{array}{c}\text { Ti Content, Saturation Magnetization, } \\
(\boldsymbol{x})\end{array}$ & $\begin{array}{c}\text { Coercivity, } \\
\mathbf{M}_{\mathbf{s}}(\mathrm{emu} / \mathrm{g})\end{array}$ & $\begin{array}{c}\text { Anisotropy } \\
\text { Constant, } \mathrm{K}\end{array}$ & $\begin{array}{c}\text { Remanent } \\
\text { Magnetization, } \mathbf{M}_{\mathbf{r}}\end{array}$ \\
\hline 0.00 & 77.31 & 1.514 & 59.567 & 0.1308 \\
0.02 & 76.40 & 1.435 & 54.817 & 0.0965 \\
0.05 & 61.50 & 1.700 & 52.275 & 0.1026 \\
0.07 & 59.50 & 1.560 & 46.410 & 0.1428 \\
0.10 & 53.70 & 1.954 & 52.465 & 0.1678 \\
\hline
\end{tabular}

Figure 9(b) illustrates the frequency dependency of magnetic loss $(\tan \delta)$. The $\tan \delta$ value declines with frequency, approaching the minimum value, and then becomes almost static. The reason behind the reduction of $\tan \delta$ with rising frequency may be above a certain frequency of applied external electric field; the motion of the domain wall may not match the external electric field. Figure 9(c) shows the variation in relative quality factor (RQF) with frequency. It is revealed that RQF rises with the increase of frequency and after a certain frequency RQF slightly decreases with frequency increase. In fact RQF has the maximum value at that frequency level where the magnetic loss tangent has the minimum value.

\subsection{Dielectric Properties}

Figure 10(a) shows the variation of dielectric constants with frequency range 1 $\mathrm{kHz}$ to $100 \mathrm{MHz}$ at room temperature. From that figure, it is evident that the dielectric constant decreases with increasing frequency at higher frequencies easily reaching constant value. The variance shows the dispersion due to interfacial polarization of the form Maxwell-Wagner [23] [24] that is confirmed by the phenomenological theory of Koop [25]. The Koop's phenomenological theory explains the higher dielectric constant values observed at lower frequencies. It may happen owing to the majority of the class of similar $\mathrm{Fe}^{2+}$ ions, oxygen vacancy, interfacial disruption pile-ups and grain boundary imperfection, etc. Due to the fact that any species paying for polarizability is bound to show the sheathing behind the applied field at higher frequencies, the dielectric constant is reduced with frequency.

Figure 10(b) indicates the frequency dependence of the dielectric loss tangent $(\tan \delta)$ at room temperature. Dielectric loss decreases as the frequency increases. The $\tan \delta$ decreases significantly with increasing frequency for each ferrite composition and becomes flat. If the frequency of the externally applied ac electric field at neighboring octahedral sites is much lower than the rate of hopping electrons between $\mathrm{Fe}^{2+}$ and $\mathrm{Fe}^{3+}$ ions, the electrons will obey the field and the loss is therefore maximum. The rate of hopping of the electron exchange between $\mathrm{Fe}^{2+}$ and $\mathrm{Fe}^{3+}$ ions at higher frequencies of the applied electric field cannot match the applied field beyond certain critical frequency [26] and the loss is the least. It is seen that with increasing $\mathrm{Ti}^{4+}$ content at lower concentration the $\tan \delta$ decreases 

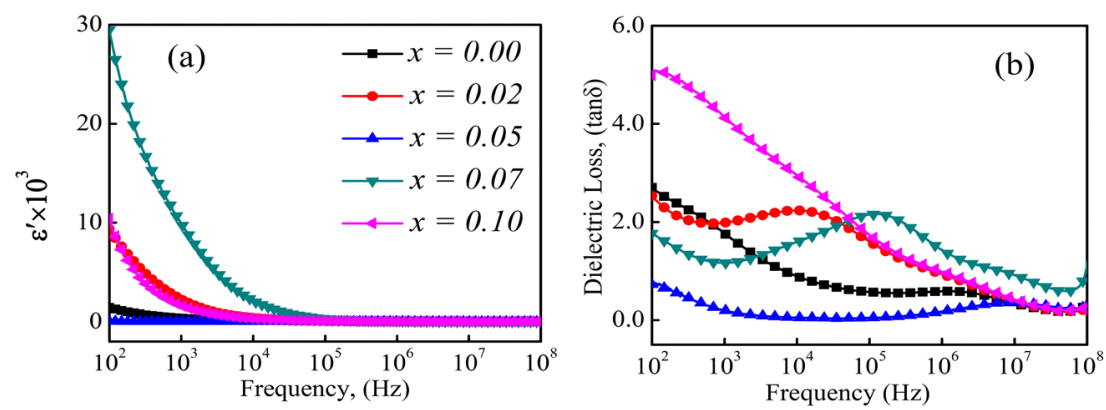

Figure 10. (a) Real part of dielectric constant as a function of frequency; (b) Dielec$\operatorname{tric}$ Loss $(\tan \delta)$ as a function of frequency.

and again increases with higher concentration this may be due to the presence of impurity in the samples although no unreacted component is seen in XRD phase identification. The values of dielectric loss may be subject to content ratio, availability of $\mathrm{Fe}^{2+}$ and $\mathrm{Fe}^{3+}$ content and mechanical stability of the composition and preparation technique.

\section{Conclusion}

In the current research, $\mathrm{Ni}_{0.4} \mathrm{Cu}_{0.2} \mathrm{Zn}_{0.4} \mathrm{Fe}_{2-x} \mathrm{Ti}_{x} \mathrm{O}_{4}(x=0.0,0.02,0.05,0.07,0.10)$ is confirmed by the solid state combustion method XRD patterns as the synthesized powder exhibiting spinel cubic structure. Increase of lattice constant with Ti content for $x=0.0, x=0.05, x=0.07 \& x=0.10$ is justified by the fact that indicates that the ionic radii of $\mathrm{Ti}$ is greater than that of $\mathrm{Fe}$ that is why lattice spacing increases for replacing $\mathrm{Fe}^{3+}(0.64 \AA)$ by $\mathrm{Ti}^{4+}(0.74 \AA)$. It is clearly visible that the theoretical density of these samples reduces linearly with the concentration of Ti except for $x=0.02$. The theoretical density decreases because the atomic mass of $\mathrm{Ti}(47.867 \mathrm{~g} / \mathrm{mol})$ is less than that of $\mathrm{Fe}(55.845 \mathrm{~g} / \mathrm{mol})$. And for $x$ $=0.02$, the X-ray density increases because in this case the lattice constant (a) decreases. The bulk density decreases initially for $x=0.02$ and $x=0.05$ is due to these two samples the microstructure contains intergranular porosity and increase of bulk density for $x=0.07$ and $x=0.10$ is due to the compact microstructure of the samples. The increase and decrease of permeability could be explained with regard to porosity. The samples with larger porosity have smaller initial permeability. Saturation magnetization decreases with the concentration of $\mathrm{Ti}^{4+}$; this might be due to lesser magnetic moment of $\mathrm{Ti}$ than that of $\mathrm{Fe}^{3+}$. The frequency dependent dielectric constant does not follow particular growth or decay for the increase in $\mathrm{Ti}^{4+}$ content may be due to the presence of some impurity point although it is unrevealed. Such observed values of magnetic parameters might make the present ferrites very useful for magnetic resonance imagining (MRI), antibacterial, catalyst and magnetic sensors. Hence $\mathrm{Ti}^{4+}$ doped $\mathrm{Ni}-\mathrm{Cu}-\mathrm{Zn}$ ferrites can be used for data storage and biomedical applications.

\section{Conflicts of Interest}

The authors declare no conflicts of interest regarding the publication of this paper. 


\section{References}

[1] Praveena, K., Sadhana, K., Bharadwaj, S. and Murthy, S.R. (2009) Development of Nanocrystalline Mn-Zn Ferrites for High Frequency Transformer Applications. Journal of Magnetism and Magnetic Materials, 321, 2433-2437. https://doi.org/10.1016/j.jmmm.2009.02.138

[2] Praveena, K., Sadhana, K. and Murthy, S.R. (2012) Elastic Behavior of Microwave Hydro-Thermally Synthesized Nanocrystalline $\mathrm{Mn}_{1-\mathrm{x}} \mathrm{Zn}_{\mathrm{x}}$ Ferrites. Materials Research Bulletin, 47, 1096-1103. https://doi.org/10.1016/j.materresbull.2011.11.054

[3] Praveena, K. and Murthy, S.R. (2013) Magneto Acoustical Emission in Nanocrystalline Mn-Zn Ferrites. Materials Research Bulletin, 48, 4826-4833. https://doi.org/10.1016/j.materresbull.2013.08.042

[4] Reddy, M.P., Kim, I.G., Yoo, D.S., Madhuri, W., Reddy, N.R., Kumar, K.V.S. and. Reddy, R.R.K. (2012) Characterization and Electromagnetic Studies on Nizn and Nicuzn Ferrites Prepared by Microwave Sintering Technique. Materials Sciences and Applications, 3, 628-632. https://doi.org/10.4236/msa.2012.39091

[5] Bacchav, S.G., Patil, R.S., Ahirrao, P.B., Patil, A.M. and Patil, D.R. (2011) Microstructure and Magnetic Studies of Mg-Ni-Zn-Cu Ferrite. Materials Chemistry and Physics, 129, 1104-1109. https://doi.org/10.1016/j.matchemphys.2011.05.067

[6] Hosseinpour-Mashkani, S.M., Maddahfar, M. and Sobhani-Nasab, A. (2016) Novel Silver-Doped $\mathrm{CdMoO}_{4}$ : Synthesis, Characterization, and Its Photocatalytic Performance for Methyl Orange Degradation through the Sonochemical Method. Journal of Materials Science: Materials in Electronics, 27, 474-480. https://doi.org/10.1007/s10854-015-3776-7

[7] Singh, A.K., Srivastava, O.N. and Singh, K. (2017) Shape and Size-Dependent Magnetic Properties of $\mathrm{Fe}_{3} \mathrm{O}_{4}$ Nanoparticals Synthesized Using Piperidine. Nanoscale Research Letter, 12, 298. https://doi.org/10.1186/s11671-017-2039-3

[8] Gyergyek, S., Makovec, D., Iztok Arcon, A.K., Jagodic, M. and Drofenik, M. (2010) Influence of Synthesis Method on Structural and Magnetic Properties of Cobalt Ferrite Nanoparticles. Journal of Nanoparticle Research, 12, 1263-1273. https://doi.org/10.1007/s11051-009-9833-5

[9] Aakash, R.C., Das, D. and Mukherjee, S. (2016) Effect of Doping of Manganese Ions on the Structural and Magnetic Properties of Nickel Ferrite. Journal of Alloys and Compounds, 668, 33-39. https://doi.org/10.1016/j.jallcom.2016.01.198

[10] Chakrabarty, S., Dutta, A. and Pal, M. (2015) Enhanced Magnetic Properties of Doped Cobalt Ferrite Nanoparticles by Virtue of Cation Distribution. Journal of Alloys and Compounds, 625, 216-223. https://doi.org/10.1016/j.jallcom.2014.10.179

[11] Rezlescu, N., Rezlescu, L., Popa, P.D. and Rezlescu, E. (2000) Influence of Additives on the Properties of a Ni-Zn Ferrite with Low Curie Point. Journal of Magnetism and Magnetic Materials, 215-216, 194-196. https://doi.org/10.1016/S0304-8853(00)00114-1

[12] Mahalakshmi, S., Srinivasa, M.K. and Nithiyanantham, S. (2014) Electrical Properties of Nanophase Ferrite Doped with Rare Earth Ions. Journal of Superconductivity Novel Magnetism, 27, 2083-2088. https://doi.org/10.1007/s10948-014-2551-y

[13] Bharathi, K.K. and Ramana, C.V. (2011) Improved Electrical and Dielectric Properties of La-Doped Co Ferrite. Journal of Materials Research, 26, 584-591. https://doi.org/10.1557/jmr.2010.37

[14] Heiba, Z.K., Mohamed, M.B., Arda, L. and Dogan, N. (2015) Cation Distribution Correlated with Magnetic Properties of Nanocrystalline Gadolinium Substituted 
Nickel Ferrite. Journal of Magnetism and Magnetic Materials, 391,195-202. https://doi.org/10.1016/j.jmmm.2015.05.003

[15] Rathi, R. and Neogi, R., (2016). Structural, Electric and Magnetic Properties of Titanium Doped Ni-Cu-Zn Ferrite. Materials Today: Proceedings, 3, 2437-2442. https://doi.org/10.1016/j.matpr.2016.04.159

[16] Pandit, A.A., Shitre, A.R., Shengule, D.R. and Jadhav K.M. (2005) Magnetic and Dielectric Properties of $\mathrm{Mg}_{1+\mathrm{x}} \mathrm{Mn}_{\mathrm{x}} \mathrm{Fe}_{2-2 \mathrm{x}} \mathrm{O}_{4}$ Ferrite System. Journal of Materials Science, 40, 423-428. https://doi.org/10.1007/s10853-005-6099-x

[17] Mali, A. and Ataie, A. (2005) Influence of Fe/Ba Molar Ratio on the Characteristics of Ba-Hexaferrite Particles Prepared by Sol-Gel Combustion Method. Journal of Alloys and Compounds, 399, 245-250. https://doi.org/10.1016/j.jallcom.2005.03.017

[18] Cullity, B.D. and Stock, S.R. (2001) Elements of X-Ray Diffraction. 3rd Edition, Prentice, Hall, Englewood Cliffs, NJ, 169.

[19] Valenzuela, R. (1994) Magnetic Ceramics. Cambridge University Press, Cambridge, 5. https://doi.org/10.1017/CBO9780511600296

[20] Ahmed, F.U., Yunus, S.M., Kamal, I., Datta, T.K., Azad, A.K. and Asgar, M.A. (1998) Neutron Diffraction Study of $\mathrm{Zn}_{\mathrm{x}} \mathrm{Ni}_{1-\mathrm{x}} \mathrm{Fe}_{2} \mathrm{O}_{4}(\mathrm{x}=0.25$ and 0.85) Ferrite. Nuclear Science and Applications, 7.

[21] Brinkman, K., Iijima, T., Nishida, K., Katoda, K. and Funakubo, H. (2007) The Influence of Acceptor Doping on the Structure and Electrical Properties of Sol-Gel Derived $\mathrm{BiFeO}_{3}$ Thin Films. Ferroelectrics, 357, 35-40. https://doi.org/10.1080/00150190701527597

[22] Smit, J. and Wijn, H.P.J. (1959) Ferrites. Philips Technical Library, Eindhoven, 150.

[23] Maxwell, K.C. (1873) Electricity and Magnetism. Oxford University Press, London, 328.

[24] Wagner, K. W. (1913) Zur Theorie der Unvollkommenen Dielektrika. Annalen der Physik, 40, 817-855. https://doi.org/10.1002/andp.19133450502

[25] Koops, C.G. (1951) On the Dispersion of Resistivity and Dielectric Constant of Some Semiconductors at Audiofrequencies. Physics Review, 83, 121. https://doi.org/10.1103/PhysRev.83.121

[26] Murthy, V.R.K. and Shobanadri, J. (1976) Dielectric Properties of Some Nickel-Zinc Ferrites at Radio Frequency. Physica Status Solidi A, 36, K133-K135. https://doi.org/10.1002/pssa.2210360247 